\title{
AS TEORIAS DA JUSTIÇA: UM CONTRAPONTO ENTRE AS CONCEPÇÕES DE JOHN RAWLS E ROBERT NOZICK
}

\section{THE THEORIES OF JUSTICE: A COUNTERPOINT BETWEEN JOHN RAWLS AND ROBERT NOZICK CONCEPTIONS}

\begin{abstract}
MARIA FERNANDA SOARES FonseCA
Mestranda no Programa de Pós-Graduação em Desenvolvimento Social (PPGDS) da Universidade Estadual de Montes Claros. mfernanda_cambuy@hotmail.com

MARIA DA LUZ ALVES FERREIRA Doutora em Ciências Humanas e Docente do Programa de Pós-Graduação em Desenvolvimento Social Stricto Sensu da Universidade Estadual de Montes Claros - UNIMONTES.

mariadaluz@oi.com.br
\end{abstract}

\section{RESUMO}

Este artigo possui o escopo de apresentar e analisar as teorias da Justiça propostas nas obras "Uma teoria da Justiça” de John Rawls e "Anarquia, Estado e Utopia” de Robert Nozick, fazendo um contraponto entre os conceitos e aplicabilidade das teorias propostas por esses dois grandes autores. Nozick e Rawls são filósofos norte-americanos com inquestionável legado na Filosofia Política contemporânea, os quais, em suas obras, debatem e apresentam seus conceitos e compreensões acerca das teorias da Justiça e sua aplicação nas sociedades democráticas contemporâneas, contrapondo-se um com o outro. Para desenvolvimento do artigo foi utilizada como metodologia pesquisa bibliográfica e documental, ou seja, trata-se de uma análise da concepção de justiça nos dois autores supracitados, no âmbito da filosofia política, objetivando realizar um contraponto entre as duas teorias e relacionando com as expressões da questão social no Brasil na contemporaneidade.

Palavras-Chave: Justiça Distributiva; Justiça como Equidade; Libertarianismo; Teorias da Justiça.

\begin{abstract}
This article aims to present and analyze the theories of justice in the works "A Theory of Justice" from John Rawls and "Anarchy, State and Utopia" from Robert Nozick, making a counterpoint between the concepts and the applicability of such theories by these two great authors. Nozick and Rawls are North American philosophers who left an unquestionable legacy in Contemporary Political Philosophy. In their works, they discussed and presented their concepts and understanding of the theories of justice and its application on contemporary democratic societies, in contrast with one another. In this study, the bibliographical and documental method were used, so this is an analysis of the conception of justice of both authors above mentioned, in the context of political philosophy, in order to present a counterpoint between both theories and relate them to the Brazilian contemporary reality expressions.
\end{abstract}

Keywords: distributive justice; justice as equity; libertarianism; theories of justice. 


\section{SUMÁRIO}

INTRODUÇAO; 1 A TEORIA DA JUSTIÇA DE JOHN RAWLS; 2 A TEORIA DA JUSTIÇA DE ROBERT NOZICK; CONCLUSÃO; REFERÊNCIAS.

\section{INTRODUÇÃO}

Hodiernamente no Brasil a credibilidade e o índice de confiabilidade nas instituições decisórias de poder são mínimos. O que se observa, principalmente através da mídia, são jornais sensacionalistas que propagam a noção da "justiça com as próprias mãos" ou a aprovação da antiga expressão "olho por olho, dente por dente", quando apresentam os crimes violentos ocorridos, além de muitas notícias de corrupção em todas as esferas dos Poderes. É possível observar, ainda, um incremento na busca, por parte dos cidadãos, da justiça como uma "salvação" ou redenção, especialmente por parte do Poder Judiciário, que é o Poder responsável por "dizer o direito" à sociedade, aplicando-o, seja condenando os autores pelos atos de corrupção, seja através da prisão e condenação no que concerne à violência e criminalidade que assolam o país. Portanto, diante do exposto, a discussão das concepções e conceitos de justiça é extremamente relevante na contemporaneidade.

Diante do aumento constante da violência urbana noticiada pela mídia e cada vez mais próxima da realidade de todo ser humano quer em bairros e cidades nobres, quer em bairros e cidades onde a pobreza predomina, reduzindo cada vez mais a distância entre homens de condutas boas e ruins, crimes sem nenhuma justificativa, o medo espalhado sem nenhum controle, surge a indagação inevitável: afinal, que é justiça? Qual seu papel na sociedade? Tais questionamentos nos remetem a estudos desenvolvidos por cientistas das mais diversas áreas do conhecimento produzindo não só respostas multidisciplinares, mas reflexões sobre os caminhos que podem ser percorridos na busca da melhoria da qualidade de vida. ${ }^{1}$

Para compreensão do significado de Justiça, e as questões a ela relativas, muitos foram os autores que se debruçaram sobre a temática, na tentativa de apresentar um conceito que esclareça as questões postas - seja no passado - e as que se apresentam na atualidade. Neste diapasão, este artigo possui como objetivo apresentar e discutir as concepções de justiça apresentadas por dois grandes autores da idade moderna, Robert Nozick e John Rawls, ambos os

${ }^{1}$ DOMINGOS, Terezinha Oliveira. A teoria da Justiça. Revista do Curso de Direito, v. 4, n. 4, 2007, p. 01. Disponível em: <https://www.metodista.br/revistas/revistas-ims/index.php/RFD/article/viewFile/ 526/\%20524>. Acesso em: 07 dez. 2015. 
filósofos de origem norte-americana com inquestionável legado na área da filosofia política contemporânea.

Robert Nozick, nascido em 1939, foi contemporâneo de John Rawls em Harvard, período em que este publicou Uma Teoria da Justiça. Três anos mais tarde, em 1974, Nozick publicou seu mais conhecido livro, intitulado Anarquia, Estado e Utopia. Esta obra ganhou espaço como uma crítica à teoria utilitarista, ao modelo anarquista norte-americano, à teoria da justiça de Rawls e estabeleceu uma utopia capitalista cuja justificação fundamental seria nunca utilizar os indivíduos como simples meios. Com isso, Nozick passou a ser conhecido como um defensor do que ele chama o Estado Mínimo e do assim chamado Libertarismo. $^{2}$

Posto isto, necessário se faz, ainda, apresentar o conceito de justiça segundo o dicionário Michaelis ${ }^{3}$ de língua portuguesa, no qual se verificam muitos conceitos,

Virtude que consiste em dar ou deixar a cada um o que por direito the pertence. 2 Conformidade com o direito. 3 Direito, razão fundada nas leis. 4 Jurisdição, alçada. 5 Tribunais, magistrados e todas as pessoas encarregadas de aplicar as leis. 6 Autoridade judicial. 7 Ação de reconhecer os direitos de alguém a alguma coisa, de atender às suas reclamações, às suas queixas etc. 8 Poder de decidir sobre os direitos de cada um, de premiar e de punir. 9 Exercício desse poder. 10 Rel Estado de graça; retidão da alma que a graça vivifica; inocência primitiva, antes do pecado do primeiro homem. 11 Personificação da justiça considerada como divindade.

Neste diapasão, Guimarães, em seu Dicionário Técnico Jurídico apresenta o conceito de justiça, a saber,

Justiça: conformidade com o direito, o preceito legal. Equilíbrio perfeito que estabelecem a moral e a razão entre o direito e o dever. Poder de julgar, de aplicar os dispositivos legais. A definição consagrada de Ulpiano: "Justiça é a vontade constante e perpétua de dar a cada um o que é seu". ${ }^{4}$

Ainda na seara do Direito, acerca da Teoria da Justiça, Montoro afirma ser um capítulo fundamental da ciência jurídica, inclusive a Filosofia do Direito. Ainda segundo Montoro "justiça é um conceito análogo, por analogia de relação ou atribuição. Em sentido direto e próprio

\footnotetext{
${ }^{2}$ BRAGA, Raphael Brasileiro. Robert Nozick e sua Teoria Política: Uma alternativa viável à proposta de John Rawls? Revista Intuitio. Porto Alegre, v.2, n. 3, nov, 2009, p. 02.

${ }^{3}$ MICHAELIS. Dicionário. Disponível em: <http://michaelis.uol.com.br/moderno/portugues/ index.php?lingua=portugues-portugues\&palavra=justi\%E7a>. Acesso em: 02 dez. 2015.

${ }^{4}$ GUIMARÃES, Deocleciano Torrieri (org). Dicionário Técnico Jurídico. 8. Ed. São Paulo: Rideel, 2006, p. 383.
} 


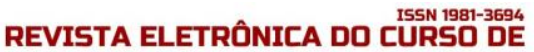

AS TEORIAS DA JUSTIÇA: UM CONTRAPONTO ENTRE AS CONCEPÇÕES DE JOHN RAWLS E ROBERT NOZICK

MARIA FERNANDA SOARES FONSECA MARIA DA LUZ ALVES FERREIRA

significa virtude ou a vontade constante de dar a cada um o seu direito. A rigor só podem ser justas ou injustas as ações humanas". ${ }^{5}$

Em conclusão, expostas algumas definições e conceitos que devem ser elucidados antes de adentrar as questões que serão apresentadas no decorrer do artigo, será utilizada a metodologia da pesquisa bibliográfica e documental para desenvolvimento da temática abordada, na qual se buscou apresentar referencial teórico consistente para apresentar as teorias da Justiça na concepção de John Rawls e Robert Nozick.

\section{A TEORIA DA JUSTIÇA DE JOHN RAWLS}

O filósofo de origem norte-americana John Bordley Rawls nascido na cidade de Baltimore no ano de 1921 e falecido em 24 de novembro de 2002, foi professor da Universidade de Harvard nos Estados Unidos da América, com graduação e doutorado em Filosofia pela Universidade de Princeton. Sua principal obra, Uma Teoria da Justiça, publicada em 1971, quando o autor tinha 50 anos, foi considerada uma das mais importantes obras da filosofia política do século XX.

Em sua trajetória pela busca do fundamento do que é o justo, o autor John Rawls retomou a tarefa primária da ética, construiu uma explicação racional para o moralmente válido e procurou compreender a lógica que define a moralidade, todavia, não no sentido de descobrir como a moralidade se dá, mas sim no sentido de como construir uma ética objetiva. ${ }^{6}$

O filósofo de Harvard John Rawls é um dos membros do clube dos grandes pensadores do contrato liberal, que incluiu entre outros T. Hobbes, J.J. Rousseau, J. Locke e I.Kant. Em 1971, publicou o seu primeiro trabalho "A Teoria da Justiça". Neste trabalho, citado extensivamente nas áreas da filosofia, politica e economia, que gerou mais discussões que qualquer outro trabalho de filósofos do séc. XX, Rawls desenvolve os princípios da justiça, que deveriam estruturar uma sociedade liberal. Inicia o seu trabalho criando uma situação hipotética, a que chama a "posição original": Os participantes têm que definir os princípios e linhas orientadoras da sua vida futura a nível político económicosocial ao longo de uma discussão onde estão cobertos pelo véu da ignorância. 0 véu da ignorância impede as pessoas de conhecer qualquer informação, incluindo

\footnotetext{
${ }^{5}$ MONTORO, André Franco. Introdução à ciência do Direito. 26 Ed. São Paulo: Editora Revista dos Tribunais, 2005, p. 165.

${ }^{6}$ THIRY-CHERQUES, Hermano Roberto. John Rawls: a economia moral da justiça. Sociedade e Estado, v. 26, n. 3, set/dez, 2011, p.551-563.
} 
AS TEORIAS DA JUSTIÇA: UM CONTRAPONTO ENTRE AS CONCEPÇÕES DE JOHN RAWLS E ROBERT NOZICK

MARIA FERNANDA SOARES FONSECA MARIA DA LUZ ALVES FERREIRA

a que lhe diz respeito, relativamente à posição na sociedade, posse de matérias primas, sexo, crenças religiosas, ranking social, etc. ${ }^{7}$

Inicialmente, é possível afirmar que a teoria da justiça de Rawls constitui, em grande parte, um posicionamento contrário ao utilitarismo clássico. Ressalta-se que a corrente utilitarista, defendida por teóricos como Jeremy Bentham e John Stuart Mill, se pauta na ideia de maximizar a felicidade e minimizar o sofrimento, em outros termos, se, para a maioria determinado fato é benéfico, então deve prevalecer - mesmo em detrimento da minoria -.

$\mathrm{Na}$ ótica do utilitarista o ideal é se obtiver máxima felicidade para um universo maior de pessoas, guiando assim os passos do legislador que deveria empenhar-se em obter a felicidade máxima para sociedade, dando origem a uma identidade de interesses entre o indivíduo e seu grupo e aplicar sanções àqueles que praticam atos que prejudiquem o bem estar de seu próximo. Em síntese, o utilitarismo é uma teoria consequencialista e teológica, pois defende que a felicidade é o resultado das ações praticadas pela sociedade como um todo. ${ }^{8}$

A seu turno, Rawls diverge dessa lógica, segundo Quintanilha "Rawls se apoia em Rousseau e, sobretudo, em Kant para apresentar seu construtivismo, que nega noções externas de justiça, afirmando uma concepção de cidadão autônomo em uma sociedade bem-ordenada". ${ }^{9}$ Em termos mais simples, segundo a mesma autora "promover vantagens aos mais desfavorecidos e uma justa igualdade de oportunidades é o que Rawls pretende com sua justiça como equidade". ${ }^{10}$

No inicio da sua obra Rawls deixa claro que pretende desenvolver uma teoria da justiça, que denomina como a justiça como equidade, e que pretende apresentar seu objeto e sua estrutura. Afirma, ainda, que seu objetivo norteador é que a elaboração dessa teoria seja uma alternativa ao que ele chama de concepções clássicas de justiça.

\footnotetext{
${ }^{7}$ FIGUEIRA, Vasco; GARCIA, Hugo. John Rawls. Disponível em http://www.liberal-social.org/john-rawls. Acesso em: 02 dez. 2015, p. 01.

${ }^{8}$ GALINDO, Cleusy Araújo. A Teoria da Justiça de John Rawls e a problemática argumentativa e principiológica entre a igualdade de oportunidades e a distribuição de riquezas. Revista Eletrônica Intr@ciência, ed. 5, 2012. Disponível em: <http://www.faculdadedoguaruja.edu.br/revista/downloads/ edica052012/artigo08_aTeoriaJusticaJohnRawlsProblematicaArgumentativaPrincipiologica.pdf>. Acesso em 10 dez. 2015, p. 03.

${ }_{9}^{9}$ QUINTANILHA, Flavia Renata. A concepção de justiça de John Rawls. Intuitio, Porto Alegre v. I.3, n. 1, jun, 2010, p.34.

${ }^{10}$ Ibid., p.35.
} 
Segundo Rawls “a justiça é a primeira virtude das instituições sociais, como a verdade o é dos sistemas de pensamento". ${ }^{11}$ Nessa esteira, ele conclui,

Portanto numa sociedade justa as liberdades da cidadania igual são consideradas invioláveis; os direitos assegurados pela justiça não estão sujeitos à negociação política ou ao cálculo de interesses sociais. A única coisa que nos permite aceitar uma teoria errônea é a falta de uma teoria melhor; de forma análoga, uma injustiça é tolerável somente quando é necessária para evitar uma injustiça ainda maior. Sendo virtude primeira das atividades humanas, a verdade e a justiça são indisponíveis. $^{12}$

Adiante, acerca do objeto primário da justiça Rawls esclarece que “é a estrutura básica da sociedade, ou mais exatamente, a maneira pela qual as instituições sociais mais importantes distribuem direitos e deveres fundamentais e determinam a divisão de vantagens provenientes da cooperação social". ${ }^{13}$ Para ele, essa questão gira em torno da justiça social.

Para determinar o que Rawls chama de “concepção da justiça como equidade” ele afirma que "uma das principais tarefas é a de determinar que princípios da justiça seriam escolhidos na posição original”. ${ }^{14} \mathrm{O}$ autor parte da premissa do que ele denomina de posição original, compreendida como um estado inicial.

$\mathrm{Na}$ justiça como equidade a posição original de igualdade corresponde ao estado de natureza na teoria tradicional do contrato social. Essa posição original não é, obviamente, concebida como uma situação histórica real, muito menos como uma condição primitiva da cultura. É entendida como uma situação puramente hipotética caracterizada de modo a conduzir a uma certa concepção da justiça. Entre as características essenciais dessa situação está o fato de que ninguém conhece seu lugar na sociedade, a posição de sua classe ou o status social e ninguém conhece sua sorte na distribuição de dotes e habilidades naturais, sua inteligência, força e coisas semelhantes (...) Os princípios da justiça são escolhidos sob um véu de ignorância. Isso garante que ninguém é favorecido ou desfavorecido na escolha dos princípios pelo resultado do acaso natural ou pela contingência de circunstâncias sociais. Uma vez que todos estão numa situação de semelhante e ninguém pode designar princípios para favorecer sua condição particular, os princípios da justiça são o resultado de um consenso ou ajuste equitativo. ${ }^{15}$

\footnotetext{
${ }^{11}$ RAWLS, John. Uma teoria da Justiça. São Paulo: Martins Fontes, 1997, p. 03.

12 Ibid., p. 04.

${ }^{13}$ Ibid., p. 07.

${ }^{14}$ Ibid., p. 15.

${ }^{15}$ Ibid., p. 13.
} 


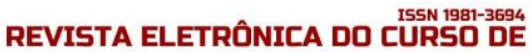

AS TEORIAS DA JUSTIÇA: UM CONTRAPONTO ENTRE AS CONCEPÇÕES DE JOHN RAWLS E ROBERT NOZICK

Defendendo a sua teoria da justiça como equidade Rawls apresenta os princípios da justiça que segundo ele, "identificam certas considerações como sendo moralmente pertinentes e as regras de prioridade indicam a precedência apropriada quando elas conflitam entre si, enquanto a concepção da posição original define a ideia subjacente que deve informar as nossas ponderações". ${ }^{16}$ São os dois princípios da justiça segundo o autor,

Primeiro: cada pessoa deve ter um direito igual ao mais abrangente sistema de liberdades básicas iguais que seja compatível com um sistema semelhante de liberdades para as outras. Segundo: as desigualdades sociais e econômicas devem ser ordenadas de tal modo que sejam ao mesmo tempo (a) consideradas como vantajosas para todos dentro dos limites do razoável, e (b) vinculadas a posições e cargos acessíveis a todos. ${ }^{17}$

Neste diapasão, sobre a formulação dos princípios de justiça na teoria rawlsiana, estes tem a função de nortear as ações das instituições básicas, os valores de liberdade e igualdade adotados para seus cidadãos, considerados livres e iguais e, principalmente, dotados de personalidade moral. Portanto, os cidadãos, que são partes integrantes da sociedade, farão desta um sistema de cooperação movido a fins. ${ }^{18}$

Importante apresentar ainda, o posicionamento de Rawls acerca da injustiça enquanto desigualdade,

Todos os valores sociais - liberdade e oportunidade, renda e riqueza, e as bases sociais da autoestima - devem ser distribuídos igualitariamente a não ser que uma distribuição desigual de um ou de todos esses valores traga vantagens para todos. A injustiça, portanto, se constitui simplesmente de desigualdades que não beneficiam a todos. ${ }^{19}$

Desta feita, de acordo com os princípios elaborados por Rawls, segundo Quintanilha “na justiça como equidade, as instituições pertencentes à estrutura básica serão justas quando puderem satisfazer os princípios de justiça escolhidos por pessoas morais, livres e iguais". ${ }^{20}$

\footnotetext{
${ }_{17}^{16}$ RAWLS, John. Uma teoria da Justiça. São Paulo: Martins Fontes, 1997, p. 56.

17 Ibid., p. 64.

${ }^{18}$ QUINTANILHA, Flavia Renata. A concepção de justiça de John Rawls. Intuitio, Porto Alegre v. l.3, n. 1. Jun, 2010.

${ }^{19}$ RAWLS, John. Uma teoria da Justiça. São Paulo: Martins Fontes, 1997, p. 66.

${ }^{20}$ QUINTANILHA, Flavia Renata. A concepção de justiça de John Rawls. Intuitio, Porto Alegre v. l.3, n. 1. Jun, 2010, p. 39.
} 
Desta forma, Rawls propõe uma concepção de justiça, a qual chamou de justice as fairnesse que seria endossada por todos os indivíduos de uma sociedade democrática caso esta deliberação ocorresse desconsiderando as arbitrariedades individuais. A justiça como equidade é a escolha mais racional e adequada para a sociedade democrática, visto que esta sociedade é marcada pelo pluralismo razoável. A justiça como equidade é elemento neutro em relação às inúmeras doutrinas abrangentes. Rawls advoga que seu conceito de justiça como equidade é político justamente por não endossar ideias particulares e privadas de doutrinas abrangentes; ela aborda apenas as ideias que possam ser publicamente reconhecidas e endossadas. Normalmente quando ouvimos a palavra justiça nos remetemos a algum conceito jurídico. No entanto, a concepção rawlsiana é de justiça política, o que significa que é um conceito que se alastra por todas as estruturas básicas da sociedade, a qual visa garantir a equidade na cooperação social. ${ }^{21}$

Em arremate ao apresentado na obra Uma Teoria da Justiça, de John Rawls, cumpre ressaltar que o autor propõe procedimentos e orientações a serem adotados pelo Estado e instituições para solução de problemas concernentes às desigualdades entre os homens, através da quebra de paradigma, ou seja, para o autor a correção das injustiças sociais se daria através de uma política que visasse à equidade (que ele apresenta como uma alternativa ao utilitarismo).

A teoria da justiça de Rawls tem eixo em uma discussão ética, histórica e social, na qual são defendidos os dois pressupostos básicos para o estabelecimento de uma sociedade com parâmetros de justiça mais aceitáveis, proporcionando igualdade de oportunidade a todos em plena condição de equidade, com distribuição dos benefícios aos mais necessitados, dando um significado à justiça e equidade, cujo primado era amparar e corrigir as desigualdades sociais. ${ }^{22}$

A teoria de John Rawls é considerada revolucionária dada o seu caráter inovador, reorientando o pensamento filosófico americano da época focado num igualitarismo teórico deixando de ser de oportunidades para ser de resultado. Foi na verdade uma resposta ao utilitarismo reinante da época (...) é salutar mencionar que o foco da Teoria de Rawls é a necessidade e premência de uma justiça justa de fato, coadunada e alinhada com os clamores daqueles que mais

\footnotetext{
${ }^{21}$ BRESOLIN, Keberson; CICHOWSKI, Vicente Cougo. Sobre o Conceito de Justiça em John Rawls e Robert Nozick. Clareira, vol. 1, n. 2. Ago/Dez, 2014, p. 130.

22 GALINDO, Cleusy Araújo. A Teoria da Justiça de John Rawls e a problemática argumentativa e principiológica entre a igualdade de oportunidades e a distribuição de riquezas. Revista Eletrônica Intr@ciência, ed. 5, 2012. Disponível em: <http://www.faculdadedoguaruja.edu.br/revista/downloads/ edica052012/artigo08_aTeoriaJusticaJohnRawlsProblematicaArgumentativaPrincipiologica.pdf>. Acesso em 10 dez. 2015.
} 
AS TEORIAS DA JUSTIÇA: UM CONTRAPONTO ENTRE AS CONCEPÇÕES DE JOHN RAWLS E ROBERT NOZICK

MARIA FERNANDA SOARES FONSECA MARIA DA LUZ ALVES FERREIRA

precisam dela os mais desfavorecidos, esquecidos pela letra da lei que desconsidera ou fecha os olhos às minorias. ${ }^{23}$

Concluindo, é importante esclarecer que a obra de Rawls, mesmo sendo um divisor de águas na seara da filosofia política, sofreu rigorosas críticas por várias correntes da filosofia.

Face às críticas sobre a concepção monológica de racionalidade implicada no seu construtivismo, Rawls reformulou alguns pontos da teoria da justiça em favor de uma noção dialógica de uma racionalidade prática. Mas manteve constantes os procedimentos e os princípios de justiça, limitando apenas o alcance da concepção, circunscrevendo o consenso aos que aceitam as concepções liberais. Nos trabalhos posteriores à Teoria da justiça, argumentou que a posição original, o véu de ignorância, seria removido por "interesses de ordem maior" que orientam os "poderes morais", a capacidade de formular, revisar e perseguir uma concepção racional do bem e a capacidade de entender, aplicar e agir de acordo com um senso de justiça. ${ }^{24}$

Necessário se faz, por fim, ressaltar que o autor John Rawls, após as polêmicas e discussões acerca da sua obra Uma Teoria da Justiça, nas décadas seguintes publicou outras obras em que pretendeu esclarecer alguns pontos de sua abordagem, inserindo a questão da esfera pública na obra Liberalismo Político (1993), internacionalizando a sua perspectiva na obra O Direito dos Povos (1999), e, também lançou as obras História da Filosofia Moral (2000) e Justiça como Equidade (2001).

\section{A TEORIA DA JUSTIÇA DE ROBERT NOZICK}

O autor da obra “Anarquia, Estado e Utopia” Robert Nozick nasceu no Brooklyn, em Nova York, em 16 de novembro de 1938 e faleceu em 23 de janeiro de 2002, em decorrência de um câncer. No ano de 1959, Nozick tornou-se bacharel em filosofia pela Columbia College, em 1963, alcançou o titulo de doutor, também em filosofia, pela Universidade de Princeton. Entre os anos de 1962 e 1969 lecionou nas Universidades de Princeton, Harvard e Rockefeller, todas nos Estados Unidos da América.

${ }^{23}$ GALINDO, Cleusy Araújo. A Teoria da Justiça de John Rawls e a problemática argumentativa e principiológica entre a igualdade de oportunidades e a distribuição de riquezas. Revista Eletrônica Intr@ciência, ed. 5, 2012. Disponível em: <http://www.faculdadedoguaruja.edu.br/revista/downloads/ edica052012/artigo08_aTeoriaJusticaJohnRawlsProblematicaArgumentativaPrincipiologica.pdf >. Acesso em 10 dez. 2015, p. 08.

${ }^{24}$ THIRY-CHERQUES, Hermano Roberto. John Rawls: a economia moral da justiça. Sociedade e Estado, v. 26, n. 3. Set/Dez, 2011, p. 560. 
Embora Nozick tenha se tornado famoso por sua defesa de um libertarianismo radical na obra Anarquia, Estado e Utopia (1974), durante seus anos de ensino médio e graduação, ele foi um socialista engajado. Como ele mesmo admite na própria obra mencionada, seu interesse pelo libertarianismo nasceu da intenção de refutá-lo. Ao desenvolver estudos para tanto, acabou convencido. Anarquia, Estado e Utopia, apesar de ser seu primeiro livro, permaneceu sempre como a obra mais conhecida de Nozick, pois foi a obra que alçou o libertarianismo a um lugar de destaque na filosofia política acadêmica e fez reviver a tradição liberal clássica na filosofia contemporânea. ${ }^{25}$ (TERCEIRO, 2015, p. 01)

Insta salientar, inicialmente, que a obra "Anarquia, Estado e Utopia”, publicada em 1974, constitui uma réplica libertária a "Uma teoria da Justiça” de John Rawls. Segundo Braga, o cerne do pensamento libertário está centrado na dignidade de cada ser humano, que não pode ser restringida em nome de nenhuma necessidade coletiva. ${ }^{26}$

Utilizamos nossa concepção de justiça de direitos a propriedades a fim de submeter a teste a teoria de Rawls, aguçando nossa compreensão do que ela envolve, ao aplicá-la a uma concepção alternativa de justiça distributiva que, por sinal, é profunda e elegante. Além disso acho que expusemos alguns defeitos profundamente encobertos na teoria de Rawls. ${ }^{27}$

O autor Nozick pode ser considerado um dos grandes teóricos do Libertarianismo, termo este que necessita ser apresentado para melhor compreensão da teoria, a seguir,

Para os libertários não é possível compreender o que é uma sociedade livre sem antes formular um sistema coerente de direitos de propriedade. A liberdade consiste em poder fazer o que se deseja e, para tanto, tornam-se indispensáveis os direitos de propriedade, pois somente assim é possível fazer o que se quer com o que se quer e onde se quer. Diante disso, o libertarismo afirma que o indivíduo possui também pleno direito de si, tendo total propriedade do seu corpo e obtendo o poder de barrar tudo o que poderia ser feito dele. Por ter direito sobre o próprio corpo, o indivíduo, consequentemente, afirmam os libertários, é senhor dos seus talentos. Caso queira, pode vender seus órgãos, estragar sua saúde ou pôr fim à sua própria existência. ${ }^{28}$

\footnotetext{
${ }^{25}$ SANTOS TERCEIRO, Ivanildo. Um pequeno guia para Robert Nozick. Disponível em <http://epl.org.br/2014/12/18/um-pequeno-guia-para-robert-nozick/>. Acesso em 02 de dezembro de 2015, p. 01.

${ }^{26}$ BRAGA, Raphael Brasileiro. Robert Nozick e sua Teoria Política: Uma alternativa viável à proposta de John Rawls? Revista Intuitio. Porto Alegre, v.2, n. 3. Nov, 2009, p. 239-256.

${ }^{27}$ NOZICK, Robert. Anarquia, Estado e Utopia. Rio de Janeiro: Jorge Zahar Editor Ltda, 1991, p. 246.

${ }^{28}$ BRAGA, Raphael Brasileiro. Robert Nozick e sua Teoria Política: Uma alternativa viável à proposta de John Rawls? Revista Intuitio. Porto Alegre, v.2, n. 3. Nov, 2009, p. 02
} 


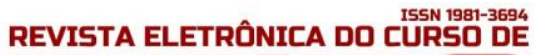

AS TEORIAS DA JUSTIÇA: UM CONTRAPONTO ENTRE AS CONCEPCCÕES DE JOHN RAWLS E ROBERT NOZICK

Segundo Braga logo nas primeiras páginas do seu livro, Nozick apresenta a sua perspectiva filosófica “[...] que os indivíduos são tão valiosos que devem ser respeitados e nenhum argumento pode refutar isso. Essa dignidade do homem é tamanha que ele não pode aceitar que nenhum de seus direitos seja violado". ${ }^{29}$

Conforme supracitado, o próprio autor inicia sua obra ratificando seus ideais libertários e apresentando suas propostas sobre o Estado Mínimo e a Justiça Distributiva, adiantando sua contrariedade às ideias de Rawls,

A parte I justifica o Estado Mínimo; a parte II alega que nenhum Estado mais amplo pode ser justificado. Prossigo argumentando que uma grande diversidade de razões, que supostamente justificam o Estado amplo, não o fazem. Contra a tese de que tal Estado se justifica, a fim de realizar ou produzir justiça distributiva entre os cidadãos, formulo uma teoria de justiça (a teoria do título ou direito, a coisas)que não requer qualquer Estado mais amplo, e o emprego do aparato dessa teoria a fim de dissecar e criticar outras teorias de justiça distributiva que propõem um Estado mais extenso, focalizando principalmente a recente e fortemente documentada teoria de John Rawls. São criticadas também outras razões em que alguém poderia pensar que justificam esse tipo de Estado, incluindo as de igualdade, inveja, controle pelos trabalhadores e teorias marxistas de espoliação. ${ }^{30}$

Diante disso, necessário se faz apresentar as ideias de Robert Nozick sobre o Estado e como ele concebe o Estado Mínimo. Conforme Braga, para Nozick o Estado nasce de um monopólio do poder, ou seja, ele supõe um Estado de Natureza no qual as pessoas formam agências para protegerem a si próprias. Segundo o mesmo autor, o que Nozick tem em mente é um Estado que possui duas características fundamentais, exercer o monopólio do uso da força em um determinado território e proteger os direitos de todos nesse território. ${ }^{31}$ Contudo, dessas agências, associações e grupamentos surgirão conflitos, em consequência disto, o autor apresenta,

[...] da anarquia gerada por grupamentos espontâneos, associações de proteção mútua, divisão de trabalho, pressões do mercado, economias de escala e autointeresse racional surge algo que se assemelha muito a um Estado mínimo ou a um grupo de Estados mínimos geograficamente distintos. ${ }^{32}$

\footnotetext{
${ }^{29}$ BRAGA, Raphael Brasileiro. Robert Nozick e sua Teoria Política: Uma alternativa viável à proposta de John Rawls? Revista Intuitio. Porto Alegre, v.2, n. 3. Nov, 2009, p. 04

${ }^{30}$ NOZICK, Robert. Anarquia, Estado e Utopia. Rio de Janeiro: Jorge Zahar Editor Ltda, 1991, p. 12.

${ }^{31}$ BRAGA, Raphael Brasileiro. Robert Nozick e sua Teoria Política: Uma alternativa viável à proposta de John Rawls? Revista Intuitio. Porto Alegre, v.2, n. 3. Nov, 2009, p. 05.

${ }^{32}$ NOZICK, Robert. Anarquia, Estado e Utopia. Rio de Janeiro: Jorge Zahar Editor Ltda, 1991, p. 31.
} 
Neste diapasão, Nozick conclui que o Estado mínimo é o mais extenso que se pode justificar, ou seja, qualquer outro Estado mais amplo viola os direitos da pessoa. ${ }^{33} \mathrm{O}$ autor apresenta em sua obra o Estado mínimo e o Estado ultramínimo.

O Estado guarda-noturno da teoria liberal clássica, limitado às funções de proteger seus cidadãos contra a violência, o roubo, a fraude, e à fiscalização do cumprimento de contratos, etc., é aparentemente redistributivo. Podemos imaginar pelo menos um arranjo social intermediário entre o plano de associações de proteção privadas e o Estado guarda-noturno. Uma vez que este último é muitas vezes denominado Estado mínimo, designaremos essa outra versão como Estado ultramínimo. O Estado ultramínimo mantém o monopólio do uso de toda a força, exceto a necessária à autodefesa imediata e dessa maneira exclui a retaliação privada (ou de alguma agência) por lesões cometidas e exigência de indenização. Mas proporciona serviço de proteção e cumprimento de leis apenas àqueles que adquirem suas apólices de proteção e respeito à leis. Pessoas que não adquirem ao monopólio um contrato de proteção, nenhuma proteção recebem. 0 Estado (guarda-noturno) mínimo equivale ao Estado ultramínimo, combinado com um plano de cupões (claramente redistributivo) friedmanesco, financiado pela receita de impostos. [...] Uma vez que o Estado guarda-noturno parece redistributivo na medida que obriga algumas pessoas a pagar pela proteção de outras, seus proponentes tem que explicar porque essa função redistributiva do Estado é excepcional. ${ }^{34}$

Os libertários que defendem as liberdades de mercado exigem limitações ao uso do Estado para a política social, portanto eles se opõem ao uso do esquema de tributação redistributiva para implementar uma teoria liberal de igualdade. Neste diapasão Nozick critica a redistribuição da tributação por acreditar que esta é uma violação aos direitos dos indivíduos, a considerar que as pessoas têm o direito de fazer o que quiserem com seus bens, e ninguém, nem mesmo o Governo, tem o direito de tirar esses bens de cada um, mesmo que seja para impedir que os menos favorecidos morram de fome. Portanto, o governo não tem o direito de interferir no mercado, mesmo que seja para beneficiá-lo. ${ }^{35}$

Segundo o mesmo autor "[...] para Nozick, se você for forçado, seja pelo Estado, seja por alguém, a contribuir para o bem-estar de terceiros, seus direitos estarão sendo violados. A teoria de Rawls dá importância à liberdade positiva das pessoas criticada por Nozick". ${ }^{36}$

Um Estado mínimo, limitado às funções restritas de proteção contra a força, o roubo, a fraude, de fiscalização do cumprimento de contratos e assim por diante

\footnotetext{
${ }^{33}$ NOZICK, Robert. Anarquia, Estado e Utopia. Rio de Janeiro: Jorge Zahar Editor Ltda, 1991, p. 42.

34 Ibid., p. 42.

35 BRAGA, Raphael Brasileiro. Robert Nozick e sua Teoria Política: Uma alternativa viável à proposta de John Rawls? Revista Intuitio. Porto Alegre, v.2, n. 3. Nov, 2009.

${ }^{36}$ Ibid., p. 04.
} 
AS TEORIAS DA JUSTIÇA: UM CONTRAPONTO ENTRE AS CONCEPÇÕES DE JOHN RAWLS E ROBERT NOZICK

MARIA FERNANDA SOARES FONSECA MARIA DA LUZ ALVES FERREIRA

justifica-se; que o Estado mais amplo violará os direitos das pessoas de não serem forçadas a fazer certas coisas e que não se justifiquem; e que o Estado mínimo é tanto inspirador quanto certo. Duas implicações dignas de nota são que - Estado não pode usar sua máquina coercitiva para obrigar certos cidadãos a ajudarem a outros ou para proibir atividades a pessoas que desejam realizá-las para o seu próprio bem ou proteção. ${ }^{37}$

Feitas as breves considerações acerca do pensamento de Nozick sobre o Estado, o Estado mínimo e o Estado ultramínimo, será apresentada adiante, a sua teoria da justiça. Nozick inicia a segunda parte de sua obra afirmando que "estudaremos a alegação de que o Estado mais amplo se justifica porque é necessário (ou é o melhor instrumento) para se conseguir justiça distributiva". ${ }^{38}$

Segundo Nozick, a expressão justiça distributiva não é neutra, “ouvindo a palavra distribuição, a maioria das pessoas supõe que alguma coisa ou mecanismo utiliza algum princípio ou critério para parcelar um suprimento de coisas. Nesse processo se distribuir parcelas - ou quinhões - algum erro deve ter-se insinuado". ${ }^{39}$ Adiante, Nozick descreve a teoria da propriedade para ratificar seus critérios acerca da distribuição.

Uma sociedade justa deve garantir a liberdade individual de se fazer o que deseja e o que quer com aquilo que se tem. Nozick não acredita em uma sociedade livre que não compreenda o direito de propriedade, pois os indivíduos possuem o direito sobre si e sobre seu próprio corpo. Portanto, qualquer forma de violação da liberdade individual, de seus bens e dos frutos do seu corpo deslegitimaria o estado, pois viola a esfera fundamental que ele nasceu para proteger. ${ }^{40}$

Portanto, para a concepção de justiça para Nozick, ele apresenta a teoria da titularidade na qual afirma que se os indivíduos são titulares de seus bens e os adquiriram de maneira justa, eles dispõem de total legitimidade para usufruir e trocá-los como lhes convier.

Para Nozick, afirma, o direito à propriedade deve ser obtido não por necessidade ou por merecimento. Ele propõe o seguinte exemplo: imaginemos que uma pessoa muito rica acabou de receber uma herança. É provável que ela não necessite dessa fortuna herdada nem mesmo tenha feito algum esforço para merecê-la. Somos, no entanto, “inclinados a dizer que a herança é sua por direito, isto é, que o herdeiro é autorizado, habilitado a ela. É nessa teoria da

\footnotetext{
37 NOZICK, Robert. Anarquia, Estado e Utopia. Rio de Janeiro: Jorge Zahar Editor Ltda, 1991, p. 09.

38 Ibid., p. 170.

39 Ibid., p. 170.

40 BRESOLIN, Keberson; CICHOWSKI, Vicente Cougo. Sobre o Conceito de Justiça em John Rawls e Robert Nozick. Clareira, vol. 1, n. 2. Ago/Dez, 2014, p. 134.
} 
titularidade da justiça que Nozick se detém". Dessa forma, não são as características pessoais que decidem quanto à justiça das posses, mas como foi obtida tal propriedade. ${ }^{41}$

Segundo Nozick referida teoria possui três características, a saber,

1. A pessoa que adquire uma propriedade de acordo com o princípio de justiça na aquisição tem o direito a essa propriedade; 2 . A pessoa que adquire uma propriedade de acordo com o princípio de justiça em transferências, de alguém mais com direito à propriedade, tem direito à propriedade; 3 . Ninguém tem o direito a uma propriedade exceto por aplicações de 1 e $2 .{ }^{42}$

Assim sendo, para o supracitado autor, é possível afirmar que se um bem foi adquirido de forma justa, toda e qualquer transferência também será justa.

Uma distribuição é justa se, por meios legítimos, surge de outra distribuição justa. Os meios legítimos de passar de uma distribuição para outra são especificados pelo princípio de justiça nas transferências. As primeiras "transferências" legítimas são especificadas pelo princípio de justiça na aquisição. (a) 0 que quer que surja de uma situação justa através de etapas justas é em si justo. Os meios de troca especificados pelo princípio de justiça nas transferências preservam a justiça da mesma forma que regras corretas de inferência preservam a verdade, e qualquer conclusão deduzida através de aplicação repetida dessas regras, baseadas apenas em premissas verdadeiras, é em si verdadeira, do mesmo modo os meios de transferência de uma situação para outra, especificados pelo princípio de justiça nas transferências, são preservadores da justiça, e qualquer situação que realmente decorra de transições repetidas, de acordo com o princípio, de uma situação justa, é em si justa. ${ }^{43}$

Conclui-se, portanto, que,

A partir da teoria da titularidade, a concepção nozickiana rejeita qualquer concepção de justiça distributiva, a qual caracterizaria uma ação por si só injusta, pois utiliza dos bens individuais legítimos dos indivíduos para potencializar a qualidade de vida da cooperação social. ${ }^{44}$

Em outros termos, a proposta de Robert Nozick gira em torno de que a base do Estado mínimo é a conservação e garantia dos direito individuais, discordando daqueles "que acreditam

\footnotetext{
${ }^{41}$ BRAGA, Raphael Brasileiro. Robert Nozick e sua Teoria Política: Uma alternativa viável à proposta de John Rawls? Revista Intuitio. Porto Alegre, v.2, n. 3. Nov, 2009, p. 15.

${ }_{42}^{42}$ NOZICK, Robert. Anarquia, Estado e Utopia. Rio de Janeiro: Jorge Zahar Editor Ltda, 1991, p. 172.

43 Ibid., p. 172.

${ }^{44}$ BRESOLIN, Keberson; CICHOWSKI, Vicente Cougo. Sobre o Conceito de Justiça em John Rawls e Robert Nozick. Clareira, vol. 1, n. 2. Ago/Dez, 2014, p. 136.
} 
que há razões para adotar um Estado menor (ultramínimo) ou mais extenso do que o Estado mínimo".45

Neste diapasão, na concepção de Nozick o Estado mínimo trata os indivíduos como invioláveis, que não podem ser usados para outros meios, sendo este o único Estado que respeita a individualidade e permite que sejam escolhidas as formas de vida que mais satisfaçam e contribuam para a realização dos nossos fins, sendo assim, não se justifica sacrificar os interesses mais fundamentais de algumas pessoas em benefício do total maior de utilidade. ${ }^{46}$

Nozick se apresenta com um pensamento libertário, o qual atribui grande ênfase aos direitos individuais. A extensão do estado deve ser mínima, ou seja, não deve existir a anarquia muito menos um estado distributivo. Neste meio, nós encontramos o estado mínimo, o qual é restrito à função de proteção (nightwatchman). A justiça é dada à medida que os direitos individuais são protegidos e maximizados. ${ }^{47}$

Diante do exposto, salienta-se a importância das questões levantadas por Nozick e da sua discussão com as proposições de Rawls, realizada ao longo de sua obra, do mesmo modo que se apresenta, de forma clara, a contraposição de concepções acerca das teorias da justiça, nas propostas de Nozick e Rawls, salientando a relevância destas diferentes correntes de pensamento para a composição de um ideal democrático, em prol de um melhor desenvolvimento social para todos os cidadãos, ressaltando que justiça não se confunde com a noção pura e simples de direito.

\section{CONCLUSÃO}

Diante de todo o exposto mister ratificar a importância e relevância inquestionável dos autores norte-americanos John Rawlse Robert Nozick, e suas obras, para a filosofia política e para a compreensão e interpretação da sociedade democrática contemporânea.

Por outro lado, os dois não possuem as mesmas proposições, ao contrário, em parte de sua obra, Robert Nozick tece elogios à Teoria da Justiça de John Rawls, enaltecendo a

\footnotetext{
${ }^{45}$ BRESOLIN, Keberson; CICHOWSKI, Vicente Cougo. Sobre o Conceito de Justiça em John Rawls e Robert Nozick. Clareira, vol. 1, n. 2. Ago/Dez, 2014, p. 137.

${ }^{46}$ BRAGA, Raphael Brasileiro. Robert Nozick e sua Teoria Política: Uma alternativa viável à proposta de John Rawls? Revista Intuitio. Porto Alegre, v.2, n. 3. Nov, 2009, p. 02.

${ }^{47}$ BRESOLIN, Keberson; CICHOWSKI, Vicente Cougo. Sobre o Conceito de Justiça em John Rawls e Robert Nozick. Clareira, vol. 1, n. 2. Ago/Dez, 2014, p. 137.
} 


\section{(1)

AS TEORIAS DA JUSTIÇA: UM CONTRAPONTO ENTRE AS CONCEPÇÕES DE JOHN RAWLS E ROBERT NOZICK

profundidade e vigor da sua obra para a filosofia política, todavia, já alerta que, em seu livro, irá destacar suas discordâncias com o pensamento de Rawls.

A semelhança de ideias entre os dois autores, é que Nozick critica, assim como Rawls, a perspectiva política utilitarista, expondo que a mesma infringe os direitos fundamentais individuais, caracterizando essa abordagem imoral $e$ inconciliável. Os autores também concordam com a máxima kantiana de tratar os indivíduos sempre como fins e nunca como meios, todavia, divergem no caminho da defesa desta máxima.

Outro posicionamento comum dos autores é que oferecem ideias fundadas nos ideais de liberdade e igualdade, divergindo, porém, por se valerem de pontos de partida distintos, atribuídos a cada um destes conceitos, de modo que Rawls objetiva propor uma sociedade fundada sob a consolidação dos princípios de justiça escolhidos de forma consensual e, em razão disto, legítimos para aplicação na estrutura básica da sociedade. A seu turno, o pensamento libertário de Nozick enfatiza os direitos individuais.

Salienta-se ainda que Rawls apresenta a sua teoria da justiça como equidade enquanto concepção política em prol do estabelecimento de uma igualdade entre os cidadãos em uma sociedade. Contrariamente, Nozick apresenta os direitos individuais como subsídio fundante de legitimação do Estado.

Sobre a divergência entre os autores, observa-se que a noção de Rawls de justa igualdade de oportunidade foi recepcionada pela maioria das concepções liberais da justiça, com exceção daqueles que corroboram com o entendimento de Nozick e acreditam que os direitos provenientes do estado natural são absolutos.

Ressalta-se, por fim, que não é objetivo do presente artigo esgotar os posicionamentos de cada um dos autores, Nozick e Rawls, acerca de suas compreensões de Justiça e Estado/sociedade. Tampouco é a intenção afirmar ser unicamente correta uma das duas Teorias Justiça. Objetivou-se, portanto, apresentar as duas concepções e fazer um contraponto entre elas, salientando a importância de ambas as obras e teorias para a filosofia política contemporânea.

\section{REFERÊNCIAS}

BRAGA, Raphael Brasileiro. Robert Nozick e sua Teoria Política: Uma alternativa viável à proposta de John Rawls? Revista Intuitio. Porto Alegre, v.2, n. 3. Nov, 2009. 


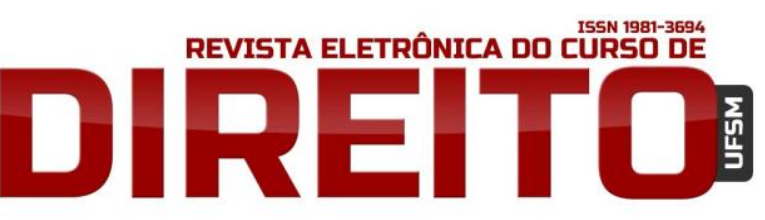

AS TEORIAS DA JUSTIÇA: UM CONTRAPONTO ENTRE AS CONCEPÇÕES DE JOHN RAWLS E ROBERT NOZICK

MARIA FERNANDA SOARES FONSECA MARIA DA LUZ ALVES FERREIRA

BRESOLIN, Keberson; CICHOWSKI, Vicente Cougo. Sobre o Conceito de Justiça em John Rawls e Robert Nozick. Clareira, vol. 1, n. 2. Ago/Dez, 2014.

DOMINGOS, Terezinha Oliveira. A teoria da Justiça. Revista do Curso de Direito, v. 4, n. 4, 2007, p. 01-20. Disponível em <https://www.metodista.br/revistas/revistas-

ims/index.php/RFD/article/viewFile/526/\%20524>. Acesso em: 07 dez. 2015

FIGUEIRA, Vasco; GARCIA, Hugo. John Rawls. Disponível em http://www.liberal-social.org/johnrawls. Acesso em: 02 dez. 2015.

GALINDO, Cleusy Araújo. A Teoria da Justiça de John Rawls e a problemática argumentativa e principiológica entre a igualdade de oportunidades e a distribuição de riquezas. Revista

Eletrônica Intr@ciência, ed. 5, 2012. Disponível em:

<http://www.faculdadedoguaruja.edu.br/revista/downloads/edicao52012/

artigo08_aTeoriaJusticaJohnRawlsProblematicaArgumentativaPrincipiologica.pdf>. Acesso em 10 dez. 2015.

GUIMARÃES, Deocleciano Torrieri (org). Dicionário Técnico Jurídico. 8. ed. São Paulo: Rideel, 2006.

MICHAELIS. Dicionário. Disponível em:<http://michaelis.uol.com.br/moderno/portugues/ index.php? lingua=portugues-portugues\&palavra=justi\%E7a>. Acesso em: 02 dez. 2015.

MONTORO, André Franco. Introdução à ciência do Direito. 26 ed. São Paulo: Revista dos Tribunais, 2005.

NOZICK, Robert. Anarquia, Estado e Utopia. Rio de Janeiro: Jorge Zahar Editor Ltda, 1991.

QUINTANILHA, Flavia Renata. A concepção de justiça de John Rawls. Intuitio, Porto Alegre v. I.3, n. 1. Jun, 2010.

RAWLS, John. Uma teoria da Justiça. São Paulo: Martins Fontes, 1997.

SANTOS TERCEIRO, Ivanildo. Um pequeno guia para Robert Nozick. Disponível em <http://epl.org.br/2014/12/18/um-pequeno-guia-para-robert-nozick/>. Acesso em: 02 de dezembro de 2015.

THIRY-CHERQUES, Hermano Roberto. John Rawls: a economia moral da justiça. Sociedade e Estado, v. 26, n. 3. Set/Dez, 2011.

Recebido em: 18/01/2016 / Revisões requeridas em: 04/07/2016 / Aprovado em: 13/07/2016 